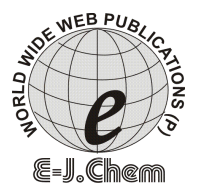

http://www.e-journals.net

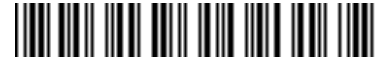

ISSN: 0973-4945; CODEN ECJHAO

E-Journal of Chemistry

Vol. 3, No.3, pp 134-136, July 2006

\title{
Derivative Spectrophotometric Estimation of Ondansetron and Paracetamol
}

\author{
P. RAVI KUMAR*, M. MURALI KRISHNA, P. BHANU PRAKASH, \\ B. ANIL KUMAR and P. MADHUSUDHAN \\ Department of Pharmaceutical Sciences, \\ Andhra University, \\ Visakhapatnam-530 003. A.P., INDIA.
}

Received 23 February 2006; Accepted 14 April 2006

\begin{abstract}
A simple and reproducible spectrophotometric method, requiring no prior separation, has been developed for the estimation of ondansetron and paracetamol in combined dosage form. First order derivative spectroscopy method is adopted to eliminate spectral interference. The methods obey Beer's Law in concentration ranges employed for evaluation. Ondansetron and paracetamol have $\lambda_{\max }$ at $302 \mathrm{~nm}$ and $246 \mathrm{~nm}$ respectively in methanol. The results of analysis have been validated statistically and recovery studies confirmed the accuracy of the proposed method.
\end{abstract}

Keywords: Ondansetron, Paracetamol, Derivative Spectrophotometry

\section{Introduction}

Ondansetron is a $5-\mathrm{HT}_{3}$ - receptor antagonist used as an antiemetic. It is official in $\mathrm{IP}^{1}$. Chemically it is 1, 2, 3, 9-tetrahydro-9-methyl-3-[(2-methyl- 1H- imidazol-1-yl)-methyl]$4 \mathrm{H}$-carbazol-4-one. Several methods ${ }^{2-4}$ have been reported for the assay of ondansetron.

Paracetamol; N-(4-hydroxyphenyl)-acetamide, is used as antipyretic. Literature survey reveals that there are UV and HPLC methods reported ${ }^{5-8}$ for the estimation of paracetamol in pharmaceutical formulations.

The review of the literature revealed that no method is yet reported for the simultaneous estimation of both the drugs in combined dosage forms. This paper describes simple, rapid, accurate, reproducible and economical method for the simultaneous estimation of ondansetron and paracetamol in tablet formulations using derivative spectrometry. 


\section{Experimental}

Spectral measurements were made on an Elico UV- Visible Spectrophotometer SL159 model with Spectral band width $1 \mathrm{~nm}$. Wavelength accuracy is $0.5 \mathrm{~nm}$ and $1 \mathrm{~cm}$ matched quartz cells. The UV spectra of ondansetron and paracetamol in various solvents show no spectral isolation. The concentration of ondansetron is 125 times lesser than paracetamol and so simultaneous estimation would have much interference. To overcome this, spectra of two drugs were derivatized from first to third orders. From the overlain spectra, first order derivative was selected for the analysis of both the drugs. The zero crossing points of ondansetron and paracetamol are $216.5 \mathrm{~nm}$ and $246.5 \mathrm{~nm}$ (Figure 1). At $216.5 \mathrm{~nm}$ ondansetron had considerable absorbance and paracetamol had zero absorbance. At 246.5 $\mathrm{nm}$ paracetamol had good absorbance and ondansetron had zero absorbance. Five mixed standards having concentrations $0.05,0.10,0.15,0.20$, and $0.25 \mathrm{mcg} / \mathrm{mL}$ of ondansetron and $6.25,12.50,18.75,25.00$ and $31.25 \mathrm{mcg} / \mathrm{mL}$ of paracetamol respectively were prepared. The absorption spectra were processed to obtain first order derivative spectra. The absorbance at $216.5 \mathrm{~nm}$ and $246.5 \mathrm{~nm}$ respectively for ondansetron and paracetamol were determined. The linearity was found to be good in the mixture at the selected wavelengths.

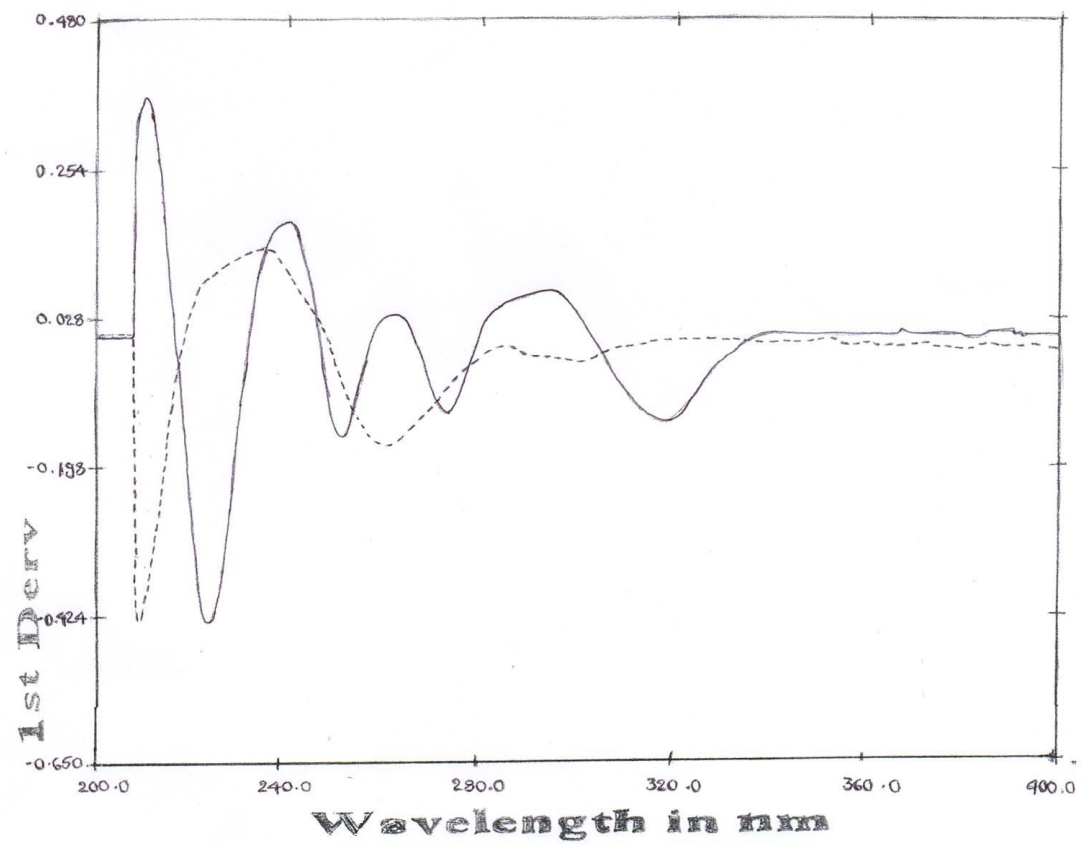

Figure 1.

\section{Procedure for the Assay of Commercial Samples}

Twenty tablets were weighed and crushed to powder. The stock solution was filtered and further diluted to get a concentration of $0.20 \mathrm{mcg} / \mathrm{mL}$ and $25 \mathrm{mcg} / \mathrm{mL}$ for ondansetron and paracetamol respectively. Absorbances were noted at $216.5 \mathrm{~nm}$ and $246.5 \mathrm{~nm}$ and concentrations of ondansetron and paracetamol were determined from respective calibration curves. The results of analysis are given in Table 1 . 
Table 1. Results of analysis

\begin{tabular}{ccccc}
\hline & \multicolumn{2}{c}{ Label claim $(\mathrm{mg})$} & \multicolumn{2}{c}{ Amount of drug found in $\mathrm{mg}$} \\
\cline { 2 - 5 } Samples & ondansetron & paracetamol & ondansetron & paracetamol \\
\hline Tablet A & 4 & 500 & 3.96 & 500.04 \\
Tablet B & 4 & 500 & 4.03 & 499.97 \\
\hline
\end{tabular}

\section{Results and Discussion}

The method developed for derivative spectrophotometric determination of ondansetron and paracetamol in tablet formulation was found to be simple and convenient for the routine simultaneous analysis of two drugs. Practically no interference from tablet excipients was observed in this method. The method is used to eliminate the spectral interference from one of the two drugs while estimating the other drug by selecting the zero crossing point on the derivative spectra of each drug as the selected wavelength. The method is accurate, simple, rapid, precise, reliable, sensitive, reproducible and economical. The values (Table 2) of standard deviation and correlation of coefficient were satisfactory.

Table 2. Validation parameters

\begin{tabular}{lcl}
\hline \multicolumn{1}{c}{ Parameters } & Ondansetron & Paracetamol \\
\hline Linearity range $(\mathrm{mcg} / \mathrm{mL})$ & $0.05-0.25$ & $6.25-31.25$ \\
Slope & 3.112 & 0.084 \\
Intercept & -0.0006 & 0 \\
Correlation coefficient $(\mathrm{r})$ & 0.999 & 1 \\
Precision (\%RSD) & 0.806 & 1.346 \\
\hline
\end{tabular}

\section{Conclusion}

The proposed method is simple, precise, accurate and rapid for the determination of ondansetron and paracetamol in combined tablet dosage forms. This method can be adopted as an alternative to the existing spectrophotometric methods. Analysis of authentic samples containing ondansetron and paracetamol showed no interference from the common additives and excipients. Hence, recommended procedure is well suited for the assay and evaluation of drugs in pharmaceutical preparations. It can be easily and conveniently adopted for routine quality control analysis.

\section{References}

1. Indian Pharmacopoeia, 1996, v II, 2062.

2. Zhang Z, Zou Q, Li W, Yan L, Xiang B and Wu R, Yaowu Fenxi Zazhi, 2002, 22(5), 386.

3. Liu C, Chen Y, Bian J, Hu H and Wang W, Yaowu Fenxi Zazhi, 2004, 24(2), 202.

4. Chandrasekar D, Ramakrishna S and Diwan P, Arzneimittel Forschung, 2004, 54(10), 655.

5. Huang X, Hou H and Wan L, Hebei Yike Daxue Xuebao, 2003, 24(6), 353.

6. Huang X R and Tang S Q, Fenxi Kexue Xuebao, 2004, 20(3), 299.

7. Shah S A, Rathod I S, Savale S S and Sutariya V B, Indian J. Pharm. Sci, 2005, 67(1), 70.

8. Sohrabi M R, Abdolmaleki P, Davallo M, Tadayyon F and Hay nollahi F, Asian J. Chem, 2003, 17(1), 117. 


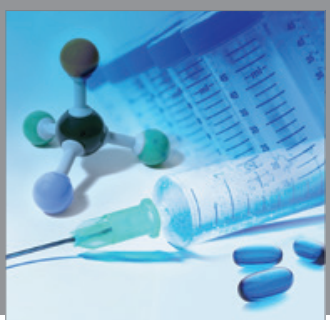

International Journal of

Medicinal Chemistry

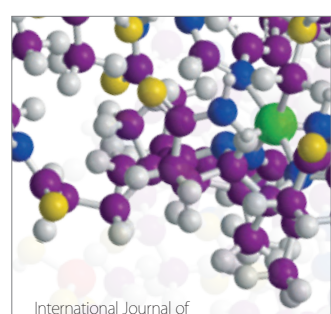

Carbohydrate Chemistry

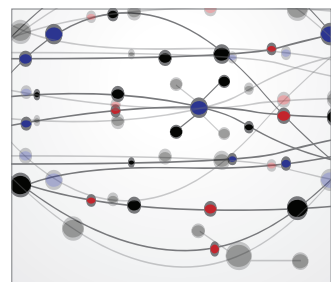

The Scientific World Journal
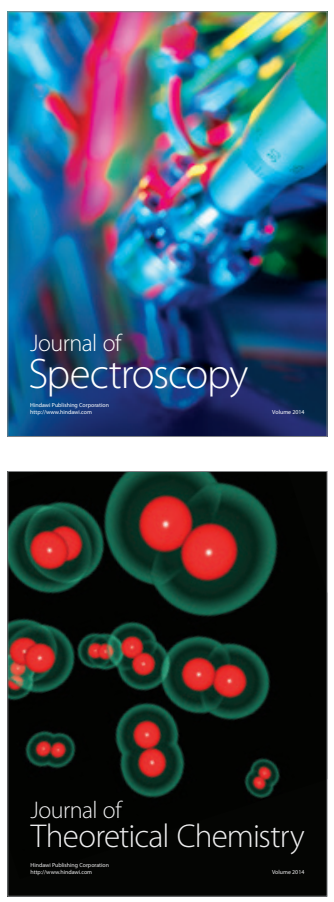
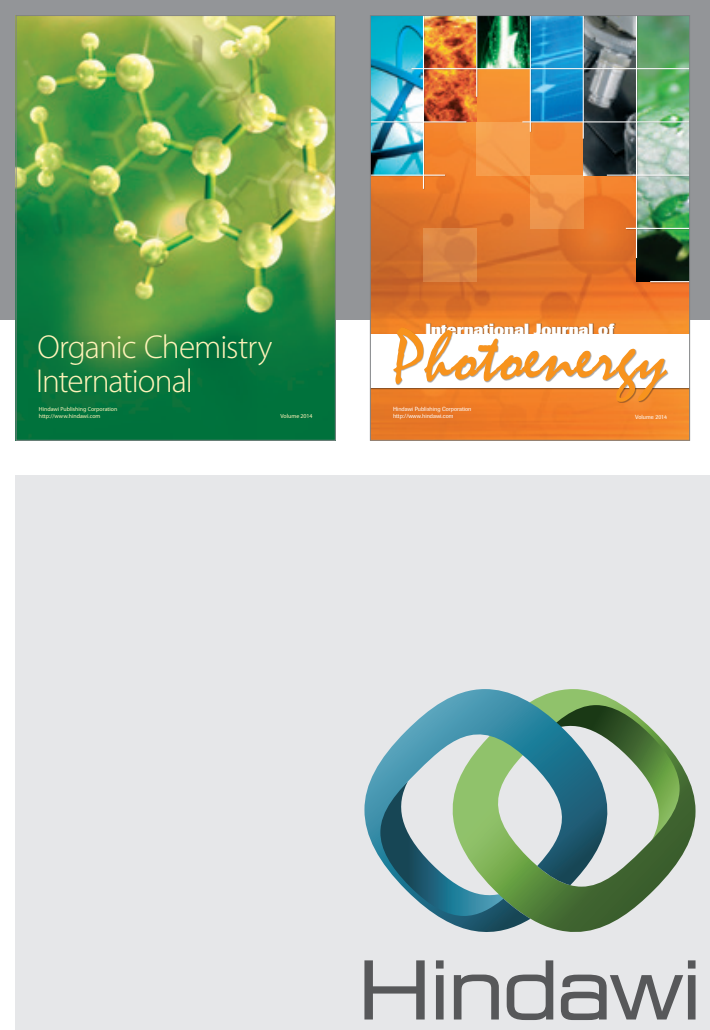

Submit your manuscripts at

http://www.hindawi.com
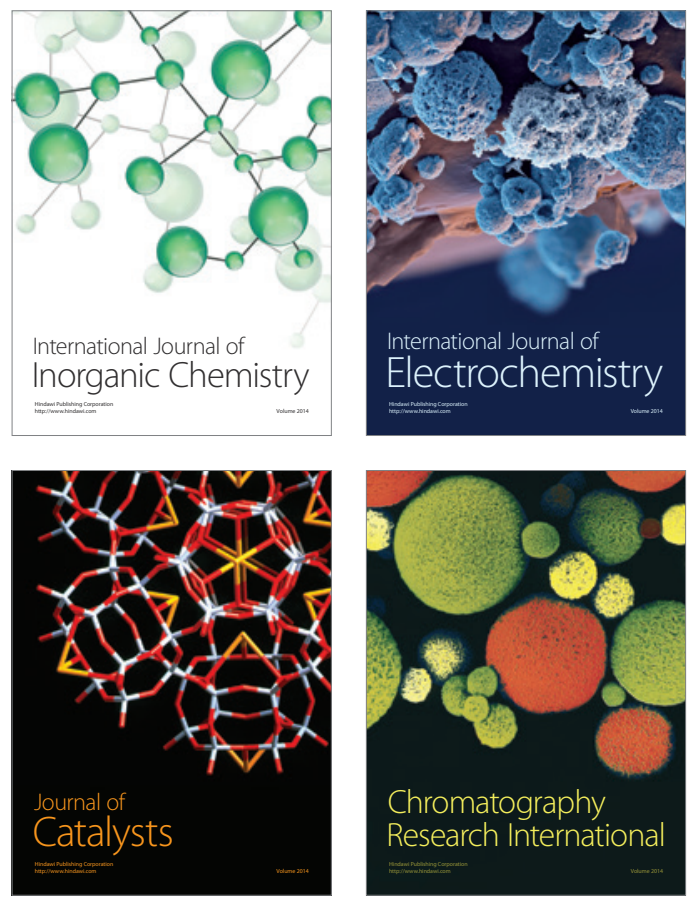
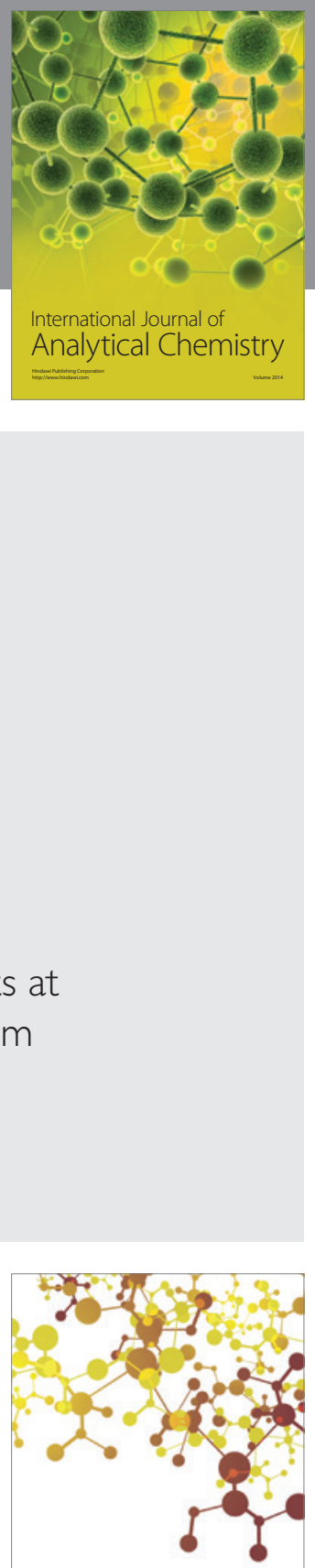

Journal of

Applied Chemistry
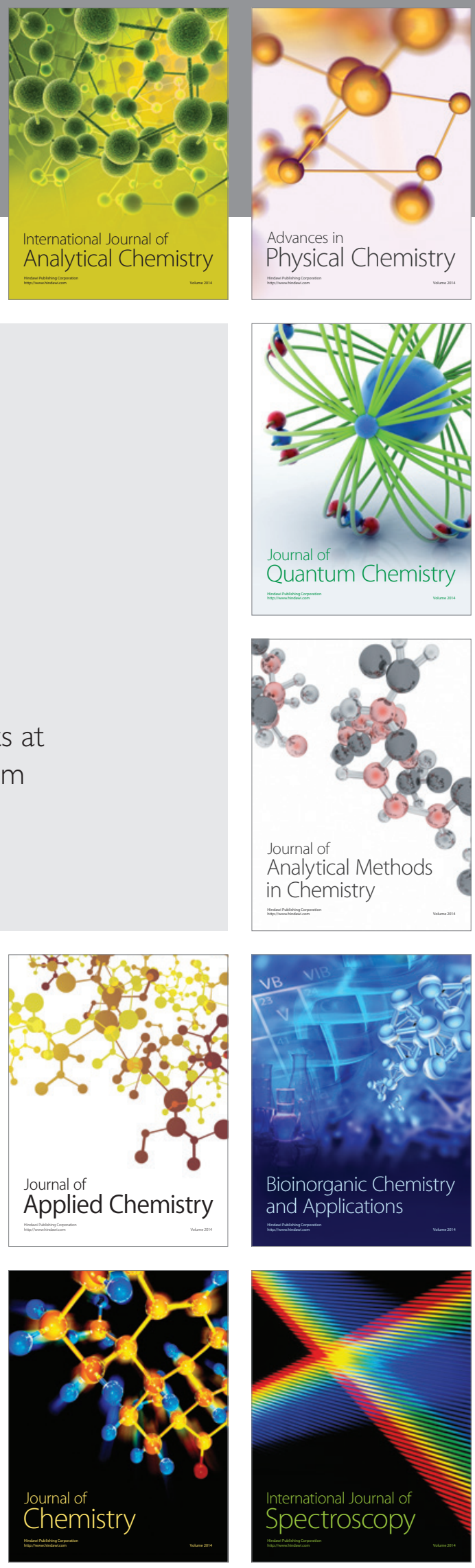